\title{
Peningkatan Kualitas Kompetensi Arbiter Syari'ah di Badan Arbitrase Syari'ah Nasional (BASYARNAS) Wilayah DIY
}

\section{Enhancement of Sharia Arbitrators on Competence Quality in the Yogyakarta Special Region National Sharia Arbitration Board}

\author{
${ }^{1}$ Fadia Fitriyanti, ${ }^{1}$ Ani Yunita, ${ }^{1}$ Muhammad Khaeruddin Hamsin \\ ${ }_{1}^{1}$ Jurusan Ilmu Hukum, Fakultas Hukum, Universitas Muhammadiyah Yogyakarta
}

Korespondensi: A. Yunita, masayunita2302@gmail.com

Naskah Diterima: 29 Agustus 2019. Disetujui: 11 Juni 2020. Disetujui Publikasi: 28 Juni 2020

\begin{abstract}
The increase in cases resolved at the Yogyakarta Special Region National Sharia Arbitration Board (BASYARNAS DIY), the limitation of Islamic arbitrators, and the lack of expertise of arbitrators in dispute resolution raises issues related to the mastery of Sharia economic law for arbitrators in BASYARNAS DIY region. This community service program aims to increase the knowledge or competence of expertise for sharia arbiter in the BASYARNAS DIY region, namely by conducting scientific discussions for Arbitrators as a basis for resolving Shariah economic disputes. The method of carrying out this dedication includes the preparation stage of scientific discussion, discussion on enhancing the competence of Sharia Arbitrators supported by pre-test and post-test during training and monitoring of evaluation activities as a reference for feedback for future discussion activities. This program was held on Friday July 26, 2019, in the meeting room of the Master of Law Degrees Program on the 2nd floor of the Postgraduate Building of Universitas Muhammadiyah Yogyakarta. The results of the community service activities were that the discussion went well and smoothly, attended by the BASYARNAS DIY Arbiter and internship students at the BASYARNAS DIY Region. With this discussion activity, the arbiter who previously did not understand about 50 percent related to the resolution of Islamic economic disputes to 100 percent really understood both materially and practically about the resolution of Islamic, disputes delivered by speakers from the National Sharia Arbitration Board and the Indonesian National Arbitration Board so the arbiter's knowledge has increased significantly.
\end{abstract}

Keywords: Enhancement, competence, National Sharia Arbitration Board, arbitrator.

Abstrak. Meningkatnya perkara yang diselesaikan di BASYARNAS DIY, terbatasnya jumlah arbiter syari'ah, dan kurangnya keahlian arbiter dalam penyelesaian sengketa maka menimbulkan persoalan terkait penguasaan hukum ekonomi syari'ah bagi para arbiter di BASYARNAS wilayah DIY. Program pengabdian masyarakat ini bertujuan untuk meningkatkan pengetahuan/kompetensi keahlian bagi arbiter syari'ah di BASYARNAS wilayah DIY yaitu dengan cara melakukan diskusi ilmiah bagi Arbiter sebagai dasar dalam menyelesaikan sengketa ekonomi syari'ah. Metode pelaksanaan pengabdian ini meliputi tahap persiapan diskusi ilmiah, diskusi peningkatan kompetensi Arbiter Syari'ah yang didukung dengan pre-test dan post-test pada saat pelatihan dan monitoring evaluasi kegiatan sebagai acuan feedback untuk pelaksanaan kegiatan diskusi kedepannya. Kegiatan pengabdian ini dilaksanakan pada hari jumat tanggal 26 Juli 2019 di ruang sidang Magister Ilmu Hukum di lantai 2 Gedung Pasca Sarjana Universitas Muhammadiyah Yogyakarta. Hasil kegiatan pengabdian ini ialah kegiatan diskusi berjalan dengan baik dan lancar dengan dihadiri oleh Arbiter BASYARNAS DIY dan mahasiswa magang di BASYARNAS Wilayah DIY. Dengan adanya kegiatan diskusi ini maka 
para arbiter yang sebelumnya kurang memahami sekitar 50 persen terkait penyelesaian sengketa ekonomi syari'ah menjadi 100 persen sangat memahami baik secara materi maupun praktik mengenai penyelesaian sengketa ekonomi syari'ah yang disampaikan oleh narasumber dari Badan Arbitrase Syari'ah Nasional Pusat dan Badan Arbitrase Nasional Indonesia sehingga pengetahuan arbiter mengalami peningkatan secara signifikan.

Kata Kunci: Peningkatan, kompetensi, BASYARNAS, arbiter.

\section{Pendahuluan}

Seiring dengan berkembangnya lembaga-lembaga Ekonomi Syari'ah, maka konsep bisnis keuangan syari'ah merupakan motor penggerak bagi perekonomian bangsa, khususnya sektor riil yang sedang berkembang. Sebagaimana praktek bisnis pada umumnya, bisnis dan keuangan syari'ah membutuhkan perangkat hukum yang cukup memadai untuk mengatur perilaku bisnis agar sesuai dengan syari'ah pada satu sisi dan hukum positif pada sisi lainnya. Pada dasarnya peraturan perundang-undangan yang ada sudah menjadi dasar hukum yang cukup kuat bagi terselenggaranya lembaga Ekonomi Syari'ah di Indonesia.

Pertumbuhan lembaga Ekonomi Syari'ah yang cukup pesat dewasa ini, menunjukkan animo dan kepercayaan masyarakat terhadap lembaga ekonomi syari'ah tersebut sangat besar. Seperti keberadaan lembaga pegadaian syari'ah dan asuransi syari'ah yang cukup mendapat perhatian dari masyarakat. Hal yang sama juga terhadap instrumen investasi yang berbasis syari'ah, seperti reksadana syari'ah, obligasi syari'ah dan instrumen investasi lainnya. Mengingat bahwa lembaga Ekonomi Syari'ah adalah lembaga keuangan yang mengedepankan moralitas dan etika, maka nilai-nilai yang menjadi dasar pengaturan, pengembangan dan operasionalnya adalah siddiq, istiqomah, tabligh, amanah, fathonah. Selain itu penerapan nilai-nilai kerjasama (ta'awun), pengelolaan yang profesional (ri'ayah, dan tanggung jawab (masuliyah) dan upaya bersama-sama terus menerus untuk melakukan perbaikan (fastabiqul khairat) (Muhammad, 2009). Oleh karena itu, dalam kegiatan ekonomi yang dilakukannya harus menjunjung tinggi nilai-nilai kepemilikan, nilai-nilai keadilan, kebebasan, keseimbangan dan persaudaraan serta kebersamaan sesuai dengan yang ajaran agama Islam.

Implementasi lembaga Ekonomi Syari'ah dalam prakteknya masih menimbulkan berbagai persoalan hukum, terutama pada pilihan penyelesaian sengketa ekonomi syari'ah. Para pihak sejak awal saat menyepakati akad sudah harus menentukan lembaga penyelesaian sengketa ekonomi syari'ah melalui badan arbitrase syari'ah atau Pengadilan Agama. Apabila para pihak menyepakati akad melalui badan arbitrase syari'ah maka saat perselisihan terjadi harus diajukan melalui Badan Arbitrase Syari'ah. Badan Arbitrase Syari'ah Nasional (BASYARNAS) Wilayah DIY merupakan lembaga penyelesaian sengketa ekonomi syari'ah di luar pengadilan (non litigasi) dibawah naungan Majelis Ulama Indonesia (Sufriadi, 2007) dan merupakan salah satu lembaga yang dijadikan mitra oleh Tim Pengabdian dalam kegiatan pengabdian ini. BASYARNAS tersebut terletak di Jalan Kapas, Semaki, Umbulharjo, Daerah Istimewa Yogyakarta.

Mengingat semakin pesatnya lembaga keuangan syari'ah dan banyaknya permasalahan yang terjadi antar lembaga keuangan syari'ah maupun antara lembaga keuangan syari'ah dan nasabah maka diperlukan Sumber daya manusia (arbiter) yang kompeten dan ahli dalam menyelesaikan sengketa ekonomi syari'ah terutama di Badan Arbitrase Syari'ah Nasional. Meningkatnya perkara yang diselesaikan di BASYARNAS DIY, terbatasnya arbiter syari'ah, dan kurangnya keahlian arbiter dalam penyelesaian sengketa maka menjadi persoalan yang harus ditemukan solusinya sehingga Tim Pengabdi yang sekaligus sebagai pengurus harian BASYARNAS Perwakilan DIY berupaya untuk meningkatkan pengetahuan dan keterampilan arbiter dalam proses penyelesaian sengketa ekonomi syari'ah di BASYARNAS DIY. 
Dalam hal penyelesaian sengketa ekonomi syari'ah, yaitu penyelesaian sengketa menggunakan arbitrase syari'ah melalui Badan Arbitrase Syari'ah Nasional. Keputusan arbitrase selalu bergantung kepada bagaimana arbiter mengeluarkan putusan yang memuaskan keinginan para pihak (Huala, 1991). Selain itu, penunjukan atau pengangkatan arbiter hanya mengacu kepada Pasal 12 Undang-Undang Nomor 30 Tahun 1999 tentang Arbitrase dan Alternatif Penyelesaian Sengketa yang menyatakan bahwa untuk dapat ditunjuk atau diangkat sebagai arbiter harus memenuhi persyaratan yaitu cakap melakukan tindakan hukum, berumur paling rendah 35 tahun, tidak mempunyai hubungan keluarga sedarah atau semenda sampai dengan derajat kedua dengan salah satu pihak yang bersengketa, tidak mempunyai kepentingan finansial atau kepentingan lain atas putusan arbitrase, memiliki pengalaman serta menguasai secara aktif di bidangnya paling sedikit 15 (lima belas) tahun (Aryani, 2011). Dari bunyi pasal tersebut dapat diketahui bahwa seseorang yang hanya memenuhi persyaratanpersyaratan tersebut diatas yang hanya dapat ditunjuk sebagai arbiter.

Meningkatnya perkara yang diselesaikan di BASYARNAS DIY, terbatasnya jumlah arbiter syari'ah, dan kurangnya keahlian arbiter dalam penyelesaian sengketa maka menjadi persoalan bagi BASYARNAS DIY. Dengan adanya beberapa persoalan tersebut maka Tim Pengabdian ini berupaya mencari solusi agar BASYARNAS DIY lebih berkompeten dalam menyelesaikan perkara ekonomi syari'ah. Pengabdian ini bertujuan untuk meningkatkan kompetensi keahlian bagi arbiter syari'ah dalam menyelesaikan perkara ekonomi syari'ah di BASYARNAS wilayah DIY, maka Tim Pengabdi menyelenggarakan kegiatan diskusi ilmiah bagi para Arbiter. Manfaat dari adanya kegiatan ini agar arbiter dan pengurus Basyarnas DIY dapat mengetahui, memahami proses penyelesaian sengketa ekonomi syari'ah dan mendukung kemampuan arbiter dalam menyelesaikan sengketa ekonomi syari'ah di Basyarnas wilayah DIY yang menjadi kewenangannya.

\section{Metode Pelaksanaan}

Tempat dan Waktu. Kegiatan pengabdian masyarakat ini dilaksanakan di ruang sidang Magister Ilmu Hukum di lantai 2 Gedung Pasca Sarjana Universitas Muhammadiyah Yogyakarta selama 6 (enam) bulan (mulai bulan Juli sampai Desember 2019).

Khalayak Sasaran. Khalayak sasaran kegiatan ini ialah sebagian arbiter di Badan Arbitrase Syari'ah Nasional (BASYARNAS) Wilayah Daerah Istimewa Yogyakarta. Badan Arbitrase Syari'ah Nasional Daerah Istimewa Yogyakarta berlokasi di J1 Kapas, Semaki, Umbulharjo, Yogyakarta. Tim Pelaksana kegiatan mengundang arbiter yang pernah terlibat dalam menyelesaikan sengketa ekonomi syari'ah di BASYARNAS DIY. Pelaksana mengundang 10 (sepuluh) Arbiter dari kseluruhan jumlah arbiter sebanyak 16 arbiter dan 3 mahasiswa Fakultas Hukum UMY yang sedang melakukan magang di BASYARNAS DIY. Para Arbiter tentunya memiliki kompetensi masing-masing baik dibidang ilmu hukum maupun syari'ah. Kompetensi keilmuan yang dimiliki para arbiter sangat mempengaruhi kualitas penyelesaian terutama pada putusan basyarnas. Oleh karena itu, perlu diadakan suatu kegiatan diskusi untu meningkatkan kompetensi kualitas para arbiter di BASYARNAS DIY.

Metode Pengabdian Metode kegiatan pengabdian ini meliputi tahap persiapan diskusi ilmiah, tahap diskusi ilmiah dan evaluasi kegiatan sebagaimana dapat dijelaskan sebagai berikut:

1. Tahap Persiapan.

Pada tahapan ini yang dilakukan oleh tim panitia ialah melakukan rapat sebanyak 2 kali untuk mempersiapkan acara pelatihan/diskusi ilmiah peningkatan kompetensi bagi Arbiter BASYARNAS. Rapat Pertama dilakukan 
pada hari Rabu tanggal 17 Juli 2019 di Ruang rapat Pusat Kajian Fakultas Hukum UMY yang dihadiri oleh tim panitia sejumlah 7 orang dan tim pengabdian sejumlah 3 orang untuk penunjukan panitia, menentukan jadwal diskusi ilmiah, menentukan narasumber, susunan acara dan pembagian tugas masing-masing panitia (Gambar 1). Untuk kelancaran pelaksanaan tugas masing-masing seksi panitia dilakukan komunikasi melalui media komunikasi. Setelah dirapatkan maka diperoleh kesepakatan untuk jadwal diskusi ilmiah yaitu pada Jumat, tanggal 26 Juli 2019 yang bertempat di ruang sidang Magister Ilmu Hukum di lantai 2 Gedung Pasca Sarjana Universitas Muhammadiyah Yogyakarta. Mengingat kapasitas ruangan yang terbatas maka panitia hanya mengundang arbiter yang aktif yaitu 10 orang arbiter dan mahasiswa magang di Badan Arbitrase Syari'ah Nasional Daerah Istimewa Yogyakarta.

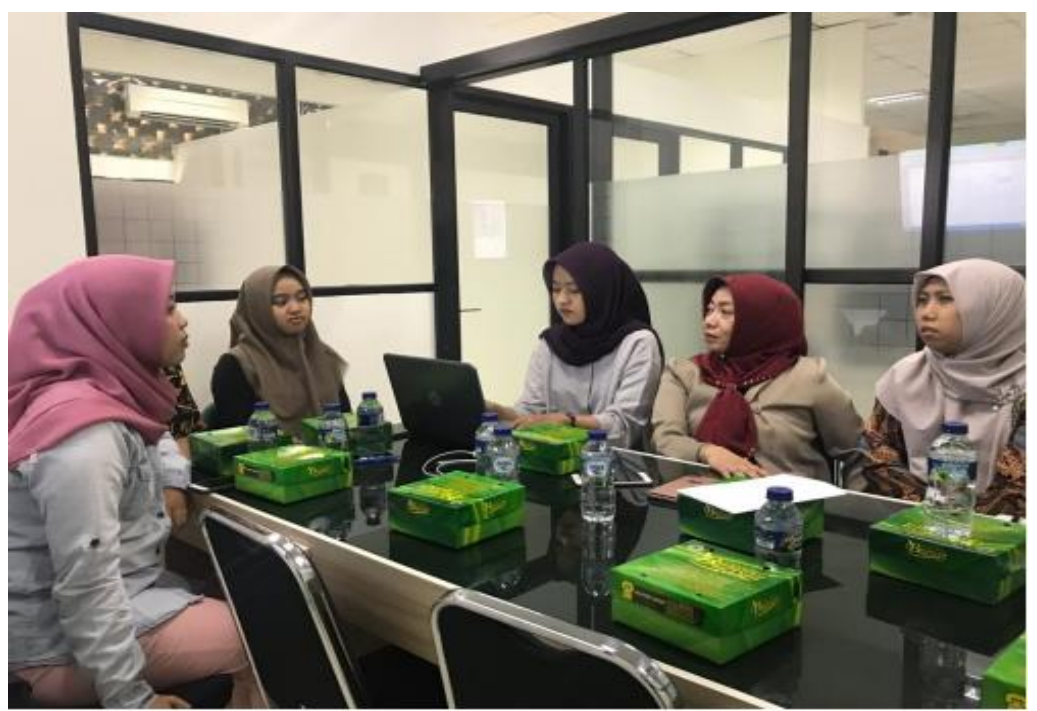

Gambar 1. Rapat Pertama Panitia Pelatihan/diskusi ilmiah

Rapat kedua dilakukan pada hari Kamis tanggal 25 Juli 2019 di Pusat Kajian Fakultas Hukum Universitas Muhammadiyah Yogyakarta yang dihadiri oleh tim pantia dan tim pengabdi (Gambar 2). Rapat ini merupakan rapat terakhir sebelum pelaksanaan hari H. Panitia mengadakan rapat bertujuan untuk berkoordinasi dan fiksasi terkait pelaksanaan acara diskusi ilmiah pada hari Jumat, tanggal 26 Juli 2019 agar berjalan dengan baik dan lancar.

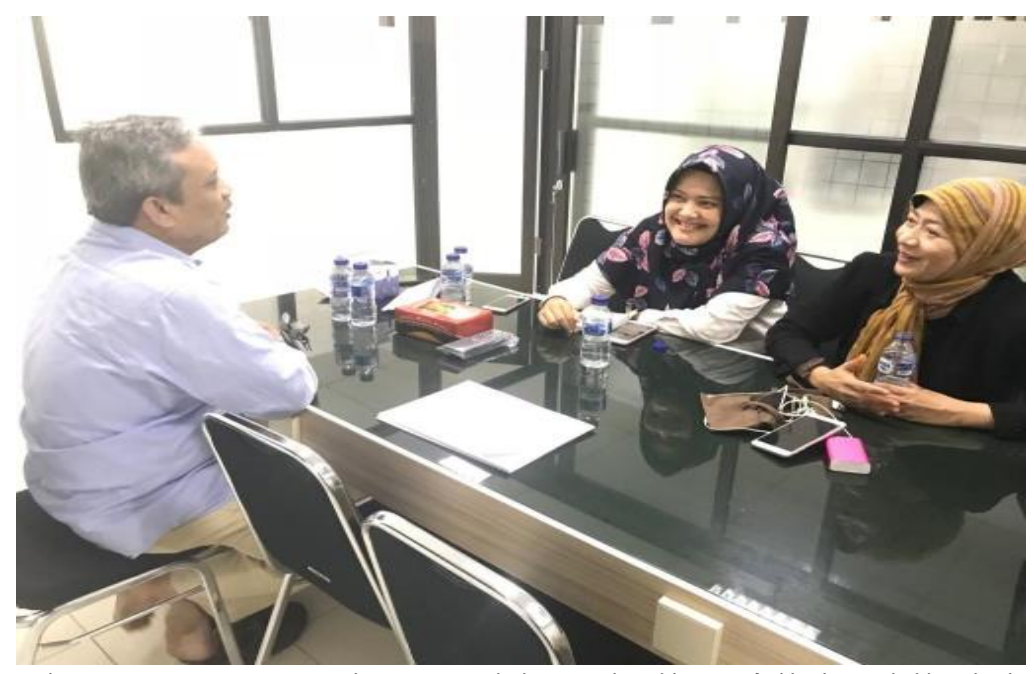

Gambar 2. Rapat Kedua Panitia Pelatihan/diskusi ilmiah 


\section{Tahapan Diskusi Ilmiah}

Tahapan diskusi ilmiah ini panitia termasuk tim pengabdi menyiapkan persiapan dan mengundang narasumber Bapak Mohammad Nur dari BASYARNAS Jakarta dan Bapak Eko Dwi Prasetyo dari Badan Arbiter Nasional Indonesia Jakarta. Metode yang digunakan oleh narasumber dalam menyampaikan materi mengenai "Tantangan dan Hambatan Badan Arbitrase dan Badan Arbitrase Syari'ah Nasional yaitu dengan menggunakan metode ceramah dan diskusi/tanya jawab secara interaktif. Selain itu, Tim panitia juga mempersiapkan bahan materi dari Narasumber untuk menjadi bahan referensi bagi peserta. Melalui metode ini maka peserta diskusi ilmiah dengan mudah dapat memahami dan mencerna materi yang disampaikan oleh Narasumber. Materi yang telah dipahami oleh peserta selanjutnya dapat diterapkan dalam menyelesaikan perkara di BASYARNAS DIY.

Indikator Keberhasilan. Indikator keberhasilan dalam kegiatan diskusi ilmiah bagi arbiter syari'ah di BASYARNAS DIY adalah peningkatan pemahaman dan pengetahuan peserta arbiter sebesar $100 \%$ pada pengetahuan penyelesaian sengketa ekonomi syari'ah yang akan digunakan dalam menyelesaikan sengketa ekonomi syari'ah di Badan Arbitrase Syari'ah Nasional di Wilayah Daerah Istimewa Yogyakarta.

Metode Evaluasi. Setelah selesai dilaksanakannya acara diskusi ilmiah maka dilakukan evaluasi di awal dan diakhir kegiatan. Metode evaluasi yang digunakan diawal kegiatan dengan mengadakan pretest dan diakhir kegiatan dengan memberikan post test dengan cara membagikan beberapa pertanyaan (kuesioner) kepada masing-masing peserta. Kuesioner tersebut dibagikan kepada peserta sebagai acuan feedback untuk pelaksanaan acara kedepannya. Post test ini dilakukan agar tim panitia mengetahui keberhasilan peserta dalam penguasaan materi terkait penyelesaian sengketa ekonomi syari'ah. Setelah pelaksanaan diskusi dilaksanakan maka panitia juga melakukan evaluasi terkait pelaksanaan diskusi ilmiah.

\section{Hasil dan Pembahasan}

Arbitrase merupakan lembaga penyelesaian sengketa di luar peradilan yang saat ini banyak diminati oleh kalangan bisnis baik nasional maupun internasional. Hal ini terjadi karena melalui lembaga arbitrase sebuah sengketa bisnis dapat terselesaikan dalam waktu yang relatif cepat dengan prosedur sederhana, serta putusan yang dihasilkan dapat lebih mudah diprediksi oleh pihak-pihak yang bersengketa (Khotibul, 2015). Salah satu lembaga Arbitrase di Indonesia ialah Badan Arbitrase Syari'ah Nasional Perwakilan Daerah Istimewa Yogyakarta yang berlokasi di J1 Kapas, Semaki, Umbulharjo, Yogyakarta. BASYARNAS DIY terdiri dari 6 orang Penasehat, 6 orang Pengurus Harian (5 orang dari 6 pengurus harian termasuk anggota arbiter) dan 16 orang Arbiter.

Meningkatnya sengketa mengenai sengketa ekonomi syari'ah dari tahun 2016 hingga tahun 2019 yang berjumlah 17 perkara yang diselesaikan melalui Badan Arbitrase Syari'ah Nasional Perwakilan DIY (Tim Pengurus BASYARNAS DIY, 2019), maka Tim pengabdi perlu meningkatkan pengetahuan dan ketrampilannya Arbiter dalam menyelesaikan sengketa ekonomi syari'ah di BASYARNAS DIY melalui suatu kegiatan diskusi ilmiah yang bertema "Problematika dan Tantangan Dalam Penyelesaian Sengketa Ekonomi Syari'ah". Kegiatan tersebut dilakukan agar kualitas kompetensi arbiter dalam menyelesaikan sengketa ekonomi syari'ah di BASYARNAS DIY mengalami peningkatan.

\section{A. Persiapan}

Sebelum dilaksanakan acara diskusi ilmiah maka pengabdi membentuk tim panitia untuk mempersiapkan acara tersebut. Pada hari Rabu, tanggal 17 Juli 2019 terbentuklah panitia dan sekaligus diadakan rapat pertama persiapan acara 
diskusi ilmiah di ruang rapat Pusat Kajian Fakultas Hukum Universitas Muhammadiyah Yogyakarta (UMY). Rapat pertama dihadiri oleh tim panitia sejumlah 7 orang dan tim pengabdian sejumlah 3 orang untuk penunjukkan panitia, menentukan jadwal diskusi ilmiah, menentukan narasumber, susunan acara dan pembagian tugas masing-masing panitia.

Rapat kedua dilakukan pada hari Kamis tanggal 25 Juli 2019 di Pusat Kajian Fakultas Hukum Universitas Muhammadiyah Yogyakarta yang dihadiri oleh tim panitia dan tim pengabdi. Rapat ini merupakan rapat sebelum pelaksanaan hari $\mathrm{H}$ yaitu pada Jumat, tanggal 26 Juli 2019. Untuk kelancaran pelaksanaan tugas masing-masing seksi panitia dilakukan komunikasi melalui media komunikasi.

\section{B. Diskusi Ilmiah}

Diskusi ilmiah ini mengundang 2 (dua) narasumber yaitu Bapak Mohammad Nur dari Badan Arbitrase Syari'ah Nasional (BASYARNAS) Jakarta dan Bapak Eko Dwi Prasetyo dari Badan Arbiter Nasional Indonesia (BANI). Metode yang digunakan oleh narasumber dalam menyampaikan materi mengenai "Tantangan dan Hambatan Badan Arbitrase dan Badan Arbitrase Syari'ah Nasional yaitu dengan menggunakan metode ceramah dan tanya jawab secara interaktif (Gambar 3).

Diskusi Ilmiah mengenai "Problematika dan Tantangan Penyelesaian Sengketa di Badan Arbitrase Syari'ah Nasional dan Badan Arbitrase Nasional Indonesia" bertujuan sebagai berikut:

1. Mengetahui berbagai problematika dan tantangan dalam penyelesaian sengketa ekonomi syari'ah di Badan Arbitrase Syari'ah Nasional (BASYARNAS).

2. Mengetahui problematika dan tantangan dalam penyelesaian sengketa di Badan Arbitrase Nasional Indonesia (BANI)

3. Memahami prosedur beracara penyelesaian sengketa di BASYARNAS dan BANI.

4. Meningkatkan Kompetensi Arbiter Badan Arbitrase Syari'ah Nasional.

5. Mengakomodir ide, masukan pemikiran solutif terhadap permasalahan hukum dalam praktik penyelesaian sengketa di BASYARNAS dan BANI.
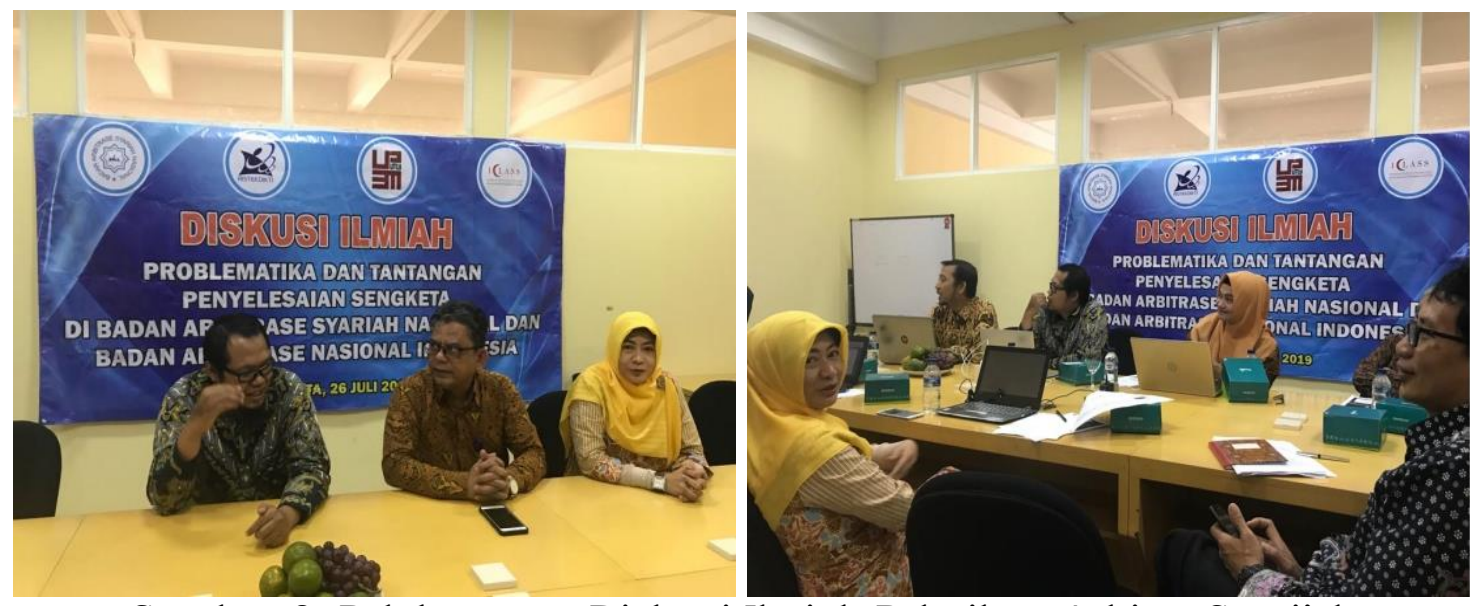

Gambar 3. Pelaksanaan Diskusi Ilmiah Pelatihan Arbiter Syari’ah

Sebelum diskusi ilmiah dimulai, tim panitia membagikan materi diskusi kepada peserta meskipun para peserta sudah memiliki pengetahuan 40-50 persen sebelum diskusi dilakukan. Pelaksana kegiatan menyelenggarakan pre-test sebelum narasumber menyampaikan materi. Pretest terdiri dari beberapa pertanyaan yang dituangkan dalam bentuk form dan harus segera dijawab oleh peserta mengenai penyelesaian sengketa ekonomi syari'ah. Pre-test ini diperlukan untuk mengetahui kemampuan awal peserta sebagai petunjuk dalam penyiapan tingkatan materi yang diajarkan sekaligus menjadi data dalam mengukur kemajuan yang dicapai peserta tekait pemahaman mengenai penyelesaian sengketa ekonomi syari'ah terutama di 
Badan Arbitrase Syari'ah Nasional DIY (Abbas, 2017). Hasil pre test bahwa diperoleh rata-rata 50 persen arbiter dapat memiliki pemahaman dan pengetahuan mengenai proses penyelesaian sengketa ekonomi syari'ah.

Diskusi ilmiah dilaksanakan pada hari Jumat tanggal 26 Juli 2019 dan berlangsung berkisar selama 5 jam yang di mulai pada pukul 07.30 s.d 11.30 WIB. Para peserta berperan aktif dan sangat antusias dalam kegiatan diskusi ilmiah dengan memberikan pertanyaan kepada narasumber sehingga diskusi berjalan secara interaktif, baik dan lancar. Selain mengadakan diskusi ilmiah, tim pengabdi juga melakukan sosialisasi kegiatan ini melalui media surat kabar kedaulatan rakyat agar masyarakat mengetahui keberlangsungan kegiatan ini dan sekaligus meningkatkan eksistensi BASYARNAS DIY sebagai lembaga penyelesaian sengketa ekonomi syari'ah. Target dalam diskusi ini ialah agar peserta mengetahui pengetahuan secara teori dan praktis terkait penyelesaian sengketa di BASYARNAS. Setelah diskusi ini berakhir, maka pelaksana membagikan post test kepada peserta diskusi. Sama halnya dengan pre test, post test terdiri dari beberapa pertanyaan yang dituangkan dalam bentuk form dan harus segera dijawab oleh peserta mengenai penyelesaian sengketa ekonomi syari'ah. Post-test ini diperlukan untuk mengetahui tingkat keberhasilan penyelenggaran kegiatan, apakah berhasil, stagnan, atau gagal.

\section{Keberhasilan Kegiatan}

Berdasarkan hasil post test diperoleh kesimpulan bahwa peserta sudah dapat memahami, menguasai mengenai tantangan, problematika dan proses penyelesaian sengketa di BASYARNAS DIY sehingga target pencapaian pemahaman peserta sebesar 100 persen. Bila di bandingkan dengan pre test maka pengetahuan dan pemahaman arbiter diperoleh rata-rata 50 persen dan post test diperoleh 100 persen. Oleh karena itu, hasil dari diadakannya diskusi ilmiah ini yang semula pemahaman dan pengetahuan arbiter hanya 50 persen menjadi 100 persen sehingga mengalami peningkatan yang signifikan.

Setelah pelaksanaan diskusi ilmiah dilaksanakan maka tim pengabdi dan LP3M UMY melakukan evaluasi kegiatan terkait keberlangsungan acara. Monitoring evaluasi dilaksanakan guna mengetahui keberhasilan kegiatan sekaligus mengukur daya serap anggaran. Indikator penilaian monitoring evaluasi, antara lain; tingkat capaian kegiatan, manfaat kegiatan bagi masyarakat, tindak lanjut dari capaian yang telah diperoleh, keterlibatan anggota tim dalam pelaksanakan kegiatan. Dan presentase daya serap anggaran dalam pelaksanaan kegiatan.

\section{Kesimpulan}

Berdasarkan hasil dan pembahasan diatas maka diperoleh kesimpulan bahwa hasil kegiatan pengabdian ini berjalan dengan baik dan lancar dengan dihadiri oleh Arbiter BASYARNAS DIY dan mahasiswa magang di BASYARNAS Wilayah DIY. Adanya kegiatan pengabdian ini dapat meningkatkan pemahaman pengetahuan bagi para arbiter sebesar 100\% (seratus persen). Dengan adanya kegiatan ini maka para peserta arbiter yang sebelumnya kurang memahami sekitar 50 persen terkait penyelesaian sengketa ekonomi syari'ah menjadi 100 persen sangat memahami baik secara materi maupun praktik mengenai penyelesaian sengketa ekonomi syari'ah yang disampaikan oleh narasumber dari Badan Arbitrase Syari'ah Nasional Pusat dan Badan Arbitrase Nasional Indonesia sehingga mengalami peningkatan pengetahuan yang signifikan.

\section{Ucapan Terima Kasih}

Penulis dalam pengabdian ini mengucapkan banyak terimakasih kepada Pihak Lembaga Pendidikan, Penelitian dan Pengabdian pada Masyarakat (LP3M) Universitas Muhammdiyah Yogyakarta sebagai pemberi dana hibah pengabdian 
Tahun 2018/2019, Ketua BASYARNAS DIY, Wakil Dekan Bidang Akademik Fakultas Hukum Universitas Muhammadiyah Yoyakarta, para Narasumber, tim panitia dan pihak lain yang terlibat dalam kegiatan pengabdian masyarakat.

\section{Referensi}

Abbas. (2017). Peningkatan Ketrampilan Bercakap Bahasa Inggris TK/TPA Di Kabupaten Takalar, Jurnal Panrita Abdi, 1(1), 40-46.

Aryani, W. (2011). Konsekuensi Hukum bagi Seorang Arbiter dalam Memutus Suatu Perkara Berdasarkan Undang-Undang No. 30 Tahun 1999. Jurnal Hukum, Vol XXV, No. 1, April 2011.

Huala, A. (1991). Arbitrase Komersial Intemasional, Rajawali Pers, Jakarta dalam Zainal A, Arbitrase dalam Perspektif Hukum Islam, Himmah Vol. VII No. 18 Januari -April 2006.

Khotibul, U. (2015). Implikasi Putusan MK Nomor 93-PUU-X/2012 Bagi Penyelesaian Sengketa Bisnis dan Keuangan Syari'ah, Jurnal Konstitusi, 12(4), Desember 2012.

Muhammad, A. (2009). Ekonomi Syari'ah Peluang Dan Tantangan Bagi Ekonomi Indonesia. Al-Iqtishad: Vol. I, No. 1, Januari 2009.

Sufriadi. (2007). Memberdayakan Peran Badan Arbitrase Syari'ah Naional (BASYARNAS) dalam Penyelesaian Sengketa Ekonomi Syari'ah di Luar Pengadilan, La Riba Jurnal Ekonomi Islam Vol 1 No.2 Desember 2007.

Tim Pengurus BASYARNAS DIY, 2019, Laporan BASYARNAS DIY Tahun 2019.

Penulis:

Fadia Fitriyanti, Fakultas Hukum, Universitas Muhammadiyah Yogyakarta, E-mail:

yantifadia@yahoo.com.

Ani Yunita, Fakultas Hukum, Universitas Muhammadiyah Yogyakarta, E-mail:

masayunita2302@gmail.com.

Muhammad Khaeruddin Hamsin, Fakultas Hukum, Universitas Muhammadiyah Yogyakarta, E-mail: oedhin2000@gmail.com.

Bagaimana men-sitasi artikel ini:

Fitriyanti, F., Yunita, A., \& Hamsin, M.K. (2020). Peningkatan Kualitas Kompetensi Arbiter Syari'ah di Badan Arbitrase Syari'ah Nasional (BASYARNAS) Wilayah DIY. Jurnal Panrita Abdi, 4(3), $290-297$. 